\title{
Excess and Withdrawal: Critical Phenomenology and Speculative Realism
}

\author{
Dustin ZIELKE
}

\section{Introduction}

Speculative realists and phenomenologists have recently had a strained relationship. For speculative realists, such as Quentin Meillassoux and Graham Harman, phenomenology is part of a correlationist tradition in philosophy that cannot adequately offer a realist approach. At the core of both Meillassoux's and Harman's projects is the problematic of correlationism. Correlationism, as we will see further below, is any philosophy that posits the unsurpassable correlation between thought and being. Or, stated in traditional phenomenological terms, it is the formal necessity of recognizing that the intended object is always correlated with an intending subject. According to Meillassoux and Harman, we need to pass beyond the phenomenological tradition to adequately attend to the real - to those things that are ontologically independent from the intentional relation.

In this paper, I will argue that a phenomenological approach can indeed offer a realist position. The intentional relation is exposed to the real as that which is ontologically independent from that relation and as that to which intentionality is only contingent. The formal necessity of the intentional relation is itself dependent upon the contingent emergence of the human into the real. The sense of realness "ascribed" to real things in the intentional relation does not ontologically nullify the objective realness or independence referred to through this sense.

To develop this argument, I take an approach that I call, for lack of a better term, "critical phenomenology." In so doing, I am not primarily concerned with defending the tradition of phenomenology, or any phenomenologist in particular, from the arguments made against them by speculative realists. Nor will I take the approach of the well-respected phenomenologist Dan Zahavi, who points to the fact that speculative realists often misrepresent the work of phenomenologists and fail to engage with the scholarly debates surrounding the interpretation of their works. Instead of taking an approach like Zahavi's, I would prefer to do phenomenology in response to the speculative realists. I use the problem of correlationism to develop a phenomenological problematic of attending to the real and 
critically delimiting it from the intentional relation. Critical phenomenology is thus critical in the sense that it sets out to understand the ontological limits of the intentional relation with respect to the real as well as the limits of the real itself.

One of the key results of this approach is to call into question Meillassoux's and Harman's forms of realism. As we will see, Meillassoux requires absolute knowledge of the real for it to be accessed by human beings. Harman, on the other hand, requires a dualism between appearances and the real object "in itself" that lies concealed beyond all appearance - in other words, a skepticism of appearances. In the following, I will show that the human being neither needs absolute knowledge about the real nor a complete skepticism of the appearance of the real in order to be exposed to the real. This exposure-however finite-is ontologically and experientially prior to these speculative demands. In simplest terms, the intentional relation is exposed to that which is independent from itnamely, the real. The most basic experience of being exposed to the real is the struggle to survive in and amongst the real. This struggle occurs before any speculative thought since real beings, such as human beings, need to first learn to survive this exposure before they have the luxury of speculating about it.

\section{Speculative Realism and Correlationism}

As many who are familiar with speculative realism already know, it takes its starting point from the so-called "problem of correlationism." This problematic was first developed in Quentin Meillassoux's work, After Finitude, where correlationism is defined as "the idea according to which we only ever have access to the correlation between thinking and being, and never either term considered apart from the other..." (5). Meillassoux begins with this problematic in order to develop a philosophy in which thought can think reality and things absolutely; that is, without the constraints and restrictions of language, context, and culture. He argues that human thought reaches this absolute level when it attends to the mathematical properties of the real. Although Harman is indebted to Meillassoux's articulation of the problem of correlationism, he takes it in a different direction, developing a unique position in speculative realism (see Harman, "Current State").

Harman contrasts his approach to that of Meillassoux by way of a two-fold reference to two foundational Kantian ideas. The first Kantian idea is the well-known division between the phenomenon and the noumenon. Whereas the phenomenon is the way that the thing appears to finite human beings through the synthesis of intuition (time/space) and understanding (the categories), the noumenon is the thing in itself. The human being has limited access to the thing in itself, which can be thought, but not known. 
The second Kantian idea concerns the privileging of what Harman calls the "human-world relation" (Harman, "Well-Wrought" 185). According to Harman, while Kant leaves it to the natural sciences to understand the relations between nonhumans, philosophy's privileged realm of inquiry is this human-world relation. Harman uses these two Kantian ideas to distinguish his response to correlationism from that of Meillassoux. Harman states that whereas Meillassoux rejects the first Kantian position (finitude) and affirms the second (the privileged human-world relation), Harman accepts the first Kantian point (finitude) and rejects the second (the privileged human-world relation) (185). I will go over these points in a little more detail.

First, whereas Meillassoux rejects Kantian finitude, Harman affirms it. For Harman, the human being cannot pass beyond its finite limits, become absolute, and access the thing in itself even through mathematics. Harman's real object is always withdrawn and inaccessible. ${ }^{1}$ Second, whereas Meillassoux accepts the Kantian privilege of the human-world relation, Harman rejects it. In other words, Harman extends finitude beyond the human-world relation such that it applies to all entities whatsoever. For example, according to Harman, when fire and cotton interact, the real fire and the real cotton withdraw away from each other. Neither one has direct access to the opposing real object. Fire only consumes the sensuous side of the cotton while the cotton's real side withdraws away from the fire (Harman, The Quadruple Object 44). For Harman, finitude is not limited to the human-world relation, but it is extended to all objects such that they never fully touch or access the real objects that underlie their sensuous sides. $^{2}$

Meillassoux's and Harman's approaches leave one with the impression that the human being either (1) can only have access to the real through the absolute knowledge of mathematics or that (2) it has no access to the real at all. In the following, I will be showing that this is a false dilemma. We are always already exposed to the real and phenomenology can help us describe this original exposure that occurs prior to any speculative approach. Because of this exposure, we know the real, however finitely, prior to any demand for absolute knowledge. And we also know

\footnotetext{
${ }^{1}$ As Zahavi notes, Harman's position seems inconsistent: “Harman's fervent endorsement of realism goes hand in hand with a radical global skepticism that forever makes reality inaccessible to us. A fact that has not prevented him from making various claims about the structure and nature of this inaccessible realm" (296).

${ }^{2}$ Harman has developed an elaborate theory of causation based upon this position that he calls "vicarious causation" (Harman, "On Vicarious Causation"). But since this theory stems from his initial dualism between real being and appearance, we need not get into the specifics of it here.
} 
the real, again however finitely, through its appearance to us in this exposure.

\section{Correlationism and "Critical" Phenomenology}

For both Meillassoux and Harman phenomenology is hopelessly correlationist. For Meillassoux, it cannot offer absolute access to the real; for Harman, it does not sever the real from appearances radically enough. But is phenomenology correlationist? This of course depends upon what one means by these terms. Let us begin with the more difficult of the two.

Phenomenology is difficult to pin down because it is a wide-ranging philosophical tradition with many names, positions, and scholarly debates associated with it. There are, I think, three main characteristics of phenomenology that can help us characterize it as a distinctive philosophical tradition. ${ }^{3}$ First, it avoids ungrounded speculative thought and abstract theoretical constructions in favor of attending to the phenomena and how they present themselves. This mandate is of course indicated by Husserl's well-known slogan to return "to the things themselves." Here, "phenomenon" and "appearance" should not be taken in a derogatory sense: unlike the Kantian and speculative traditions, phenomenology does not impose the metaphysical dualism of reality versus appearance on that which appears. ${ }^{4}$ That is, the being of the phenomenon is located in the dynamic of

3 As any anthology on phenomenology would show, phenomenology is a broad philosophical tradition with various approaches (eidetic, existential, hermeneutic). I see no reason to limit phenomenology to Husserl's middle-period transcendental idealism, as does Tom Sparrow. This allows Sparrow to claim that everything that does not strictly follow this method is not really phenomenology while simultaneously establishing that phenomenology cannot then be realist because Husserl's method brackets metaphysical claims. Zahavi has responded to Sparrow at length. To draw on another authority, we could point to Heidegger's Husserlian influenced statement, “...phenomenology is so far from being a 'method' that we must glean the mode of examination from the things themselves [den Sachen selbst]" (The Concept of Time 11).

${ }^{4}$ This is true for Husserl, Heidegger, and Sartre. The case is more complex with Sartre because of his idiosyncratic phenomenological ontology. Although Sartre clearly articulates the mainstream phenomenological position, which rejects the dualism between reality and appearance, Sartre still posits two basic terms that seem to reinstate this difference, the in-itself and the for-itself. Sartre's English translator, Hazel E. Barnes, indicates that although Sartre thought of himself as a phenomenologist he also did not exactly follow the phenomenological orthodoxy. Barnes writes, "He [Sartre] says that in formulating metaphysical hypotheses to guide us in phenomenological psychology...we may, as we like, keep the old being-consciousness dualism or adopt a phenomenon which will be provided with two dimensions of being (In-itself and For-itself). But such hypotheses we may use only as the physicist may employ ad libitum either the wave theory or the quanta theory; that is, not with the idea that either is an exhaustive description but that it is merely an expedient hypothesis within which one may carry out experiments" (Sartre, Being and Nothingness xxv). It seems then that despite his understanding of the 
its presencing and withdrawal, in its appearance and hiding, and not behind the phenomenon in some noumenal or metaphysical realm. For instance, if we are talking about real things, the realness of these things is found in their appearance as real. This is not to say that all that appears as real is actually real (e.g., hallucinations). It is rather to say that even that which deceptively appears as real must take on the appearance of realness in order to be mistaken as real in the first place.

Second, and following from the first point, to allow the phenomenon to show itself from itself requires that the phenomenologist does not impose pre-given theoretical viewpoints, concepts, or ideas that do not take their lead from the phenomenon or cannot be intuitively fulfilled by the phenomenon itself. For instance, from the perspective of phenomenology, the metaphysical dualism between a phenomenon and its noumenon in Kant's thought is a metaphysical remnant, stemming from his desire to reserve a systematic place for an infinite being (i.e., God) in his thought (Heidegger, Kant 16-17, 21-22). Since neither the noumenon, nor the infinite being who is correlated with it, appear to finite beings, they must first be postulated to be "over and above" the phenomenon or "behind it" in an inaccessible, metaphysical realm. This is precisely the kind of speculative move that phenomenologists resist by sticking with the phenomenon. Realness is not located on another metaphysical plane but in the phenomenon of the real itself.

Third, phenomenology is not an empirical investigation about phenomena. As phenomenology, it does not seek to verify whether the phenomenon of a tree is actually a real tree in the real world through empirical investigation. Or, to put it otherwise, it does not seek to falsify the phenomenon through an empirical method. Instead, it clarifies the sense of realness that is given by the phenomenon and which, first of all, guides empirical investigation of the real. However, this does not mean that phenomenology cannot be scientifically informed. The results that science disseminates to non-scientific audiences filter down into the very understanding that accompanies any experience of the world. Thus, when I see stars at night, I do not see pinholes in the floor of heaven as the ancients did, but I see distant astral bodies. Phenomenology seeks to clarify the sense of the phenomenon and this disseminated scientific knowledge about the phenomenon would be a part of the experience phenomenology explicates. If it is a phenomenology of empirical or natural scientific investigation, it seeks to show how empirical methods and scientific research are possible in the first place. ${ }^{5}$ And if it is a phenomenology of the real, then it seeks to

phenomenological position on this point, Sartre saw no problem re-instating this dualism in order to carry out the thought-experiment that is Being and Nothingness.

${ }^{5}$ See, for instance, Harvey \& Shelton. From a Heideggerian perspective, see Heidegger, "Science and Reflection." 
clarify the sense of the real that has been shown by the phenomenon of the real and which underpins any empirical approach to real things.

Moving on, we have seen that correlationism is a philosophical position holding that the relation between being and thought is necessary and unsurpassable. One cannot, so the correlationist would say, think being without thinking it. To translate this into traditional phenomenological language, correlationism would be equivalent to affirming the necessity of the correlation between the noetic and noematic side of the intentional relation. The intending subject must necessarily be in relation to the intentional object, since the object is an intended object.

Applied to phenomenology, the problematic of correlationism would then require showing how a real object, even if intended, is not ontologically reducible to the intentional relation itself. That is, the referent of the sense of realness that the object shows as a real thing is not dependent upon the presence of the subject that intends it. The sense of realness is itself simply the revelation of the objective realness (or what I will call below its "act of existing") that lies independently in the real thing and it would "be there" even if the intending subject was not. The sense of this realness (as it is revealed specifically to an intending subject) could not be there without the subject. But the ontological origin of this sense to which the sense refers, that is, the objective realness of the object, could be there without the intending subject and its sense. This also implies that the very sense of the objective realness of the object indicates the contingency of the intentional relation itself.

Taken from a phenomenological point of view, the problematic of correlationism can be summarized in the following way. First, it must be shown that thought can intend something (i.e., the real) that is ontologically irreducible to the intentional relation. Second, it must be shown that the intentional relation implicitly recognizes its own contingency with regard to what it intends (i.e., the real). It is in this sense that I will be speaking about being exposed to the real. In its encounter with the real, the intentional relation is exposed to something that would be there even if the intentional relation was not. There is a complication here since, as we will see, the intentional relation or the presence of the human within the real unleashes potentials in and for the real that would not be there if the human was notwhat I will call below "transobjective potentials." One such transobjective potential is the reception of the sense of realness, which stems from an independent act of existing that would be real regardless of the presence of this sense or the subject that has this sense. Nevertheless, the realness of the real is not ontologically reducible to these transobjective potentials since these potentials are, as is the presence of the human in the real, contingent and emergent. In being exposed to the real, the human is exposed to a field of experience that was there prior to its emergence and that would be there 
even if the human was not. That is, being exposed to the real indicates the contingency of the intentional relation itself with regard to the real.

For lack of a better term, I will be calling my approach to developing and thinking through this problematic, "critical phenomenology." It is critical in two senses. First, it is critical in the sense that it critically delimits the intentional relation from the real, exposing it to the ontological independence of the real and the intentional relation's contingency within the real. Second, it is critical in that it critically delimits the phenomenon of the real from the intentional relation such that Meillassoux's and Harman's responses to the problematic of correlationism come under suspicion. In other words, the intentional relation neither needs to be an absolute knowledge of the real (as with Meillassoux) nor a complete severance from the real (as with Harman) in order to be exposed to the real. The phenomenon of exposure is ontologically and existentially prior to these speculations about the real. It neither stems from absolute knowledge, nor from a total skepticism about appearances, but rather from the oldest experience of struggling and surviving within and amongst the real.

\section{The Phenomenology of the Real}

The following will be a formal description of the real that aims to display the real within material limits. Just because this analysis is formal does not mean that it is not phenomenological. The intuition of the phenomenon here, which is the evidence of the phenomenon itself in phenomenology, intends to be a description of the real itself regardless of what type of real, material being it is. The intuition that is supposed to be the evidence is not applied to any given type of real entity. Yet, the very coherence and (ideally) descriptive-power of the following, its ability to show the phenomenon of the real, is meant to be its evidence. As with other phenomenologists like Husserl and Heidegger, intuition does not necessarily mean sensuous or perceptual intuition. It can be the description of the type itself, that is, the form or the ontological delimitation of the real that is in question and being described. The following is a formal indication of the ontological characteristics of the phenomenon of the real.

Contra Meillassoux's claims, the real need not be absolutely known in order for humans to "have access" to it. Human beings are embedded within the real and exposed to it prior to any philosophical requests to know it absolutely. The description of the real arises out of this prior exposure to it and by reflecting on this exposure. Nor is the real, as it is for Harman, something other than the things that appear in relation to one another. The "withdrawn" or "excessive" quality of the real is found in the way that no real thing can be reduced to the set of actual material relations to which it belongs. However, this excess in the real is not located in some metaphysically inaccessible realm, as it is for Harman. Instead of 
postulating a speculative realm in which the "really real" exists apart from all relations, I would suggest that this "realm of withdrawal and excess" is itself real. It is a realm of real, but unactualized potential. This realm is real in that it has real limits: namely, what we usually call material causality. Just like the actual real, these unactualized potentials of the real are limited by those descriptions that science lifts off and reads off the patterns and regularities in the real-otherwise known as "natural laws." Because of these limits, this realm, which includes unactualized potential, can be understood even if it is too vast, complex, and sometimes too chaotic to be fully known by finite creatures. I will call this realm that preserves the excess in the real "the universe." The universe holds the actual real in potentials that may or may not be actualized and preserves each real thing in its individual uniqueness.

As one may have already noticed, both the real and the universe are real. Realness refers to the actual real and to the potential of the real-which may or may not be actualized. Realness can refer then to unactualized potentials. These are real if they could have happened, given the state of the real at a given time and given the causal relations that both open up and delimit the real's potential.

One of the phenomenological insights here that might strike readers as somewhat difficult is the idea that material causality is not conceived as the origin of the real, but as both an emergent and delimiting condition of the real. Given the way that science has replaced metaphysics and religion, material causation may appear as the explanation for the origin of the real. One might even be tempted to treat natural laws as if they themselves were causal agents. ${ }^{6}$ But, natural laws need not be understood in this way. I will be speaking about material causality as an immanent condition within the real, not a transcendent "dial and knob" that fine-tunes the universe from the outside or as a "spectral agency" that gives rise to the real. The natural laws that science talks about are reflections of regularities and patterns in the real. They have emerged through the history of the real itself. That is, the laws that science explicates are emergent from the history of the real, not some condition that is placed upon it or some spectral causal "agent" that explains it from the beginning. In this respect, material causality is an emergent conditioning of the real for the real itself. It arises from the real and the way it plays itself out, opening up potentials for the real but also restraining these potentials because of the "weight and consequence" of the

${ }^{6}$ For instance, some non-professional readers have interpreted Hawking \& Mlodinow's argument to mean that the natural laws or the fine-tuned physical laws of our universe have caused the emergence of this universe. I do not understand Hawking \& Mlodinow's argument in this way. But I do understand the "amateur" temptation to replace the traditional efficient cause (i.e., God) of the universe with another spectral agency such as natural laws, as if they were transcendent conditions placed upon the universe and the real before it even began, as if from the outside-in. 
real's past. These potentials are always already limited by the history of the regularities and patterns that the real has already set for itself. The real past is not determinative of what actually happens, but it does set limits on what can happen. Material causality is the name for this limitation on what can happen in the real, one which does not preclude the emergence of novel events or forms of existence.

Following from this, there is a second difficulty. Calling the field that preserves this capacity for the real to happen within limits "the universe" means that the universe far exceeds what actually happens. It simultaneously includes unactualized potentials alongside potentials that have been or will be actualized in the real. As we will see further below, the real refers to the field of actualized and actualizing material things. The universe encompasses the real, but it also includes within it those unactualized potentials that belong to the real as its excess. For instance, the universe is the "place" where I could have chosen to not go to graduate school even if it is simultaneously the place where I did choose to go to graduate school. In the real, I went to graduate school. And I live in a universe where I have gone to graduate school "in the real." But despite this having happened in the real, the universe preserves within it the unactualized potential of my past: for me to have not gone to graduate school and to have done something else with my life. The universe is thus more encompassing than the real: it contains more potentials than those that have been or will be actualized by the real.

\section{a) The Real as Actual and Material}

The real refers to actually existing material things. To be actual is to be in the act of existing. This act of existing should be understood formally, that is, it does not necessarily refer to contemporary acts of existing. In addition to contemporary acts of existing, it can also refer to acts of existing in the distant past and distant future. In each case, regardless of its chronological position, a real thing occurs in and through an act of existing. Every act of existing is durative or constantly enacted, opening temporal and spatial relations to other acts of existence. ${ }^{7}$ If certain acts of existing are simultaneous, they open up the progression from the near past into the present and the near future. And they also open up a momentary and constantly changing space - either near or far. If certain acts of existence are non-simultaneous, they open up the distant past, the distant future, and the temporal progression between them (including the present) that is exposed to this distant and/or deep time.

\footnotetext{
${ }^{7}$ For a post-Kantian understanding of real things granting time-space or opening up time and space as temporalizing and spatializing entities, see Heidegger, "The Thing." See also Heidegger, "Building, Dwelling, Thinking."
} 
In addition to referring to actual things, the real also refers to material things. Material things (1) are temporal-spatial and (2) have the capacity to be materially affected by and to have material effects on other real things. I have already commented on the temporalizing and spatializing aspects of acts of existing. The key point here is that time and space are opened up by the durative and either simultaneous or non-simultaneous acts of existing of individual real things. Time and space are the most general names for relations amongst individual acts of existence.

The real is also material in the sense that it is affected by and has material effects on other real things. In other words, the real occurs within and gives rise to a material context of causal relations. A real thing is not only affected by the material conditions and relations that influence its own existence, but it also contributes to its environment and modifies those material relations as a causal "agent." 8 In being affected, there is always an immanent reception within the thing of how it will be affected by others. This "how" not only follows the type of real being it is and its typical ways of responding to this being affected, but it also follows the contingency of its own irreducibly unique and individual characteristics. And this immanent response in each individual real thing is then extended out onto its material effects (or limitations) on others. Its individual response affects others uniquely and, along with them, it actively constitutes the specific and singular context in which it occurs.

The history of the real (what has actually happened) is that which gives rise to the field of potential, a field that is limited by causal restraints. This history includes regularities and patterns that emerge immanently within and through the real. The regularities and patterns within the real accumulate and accrue within it, setting limits on what can actually happen within the real. The "natural laws" described by science belong to a secondlevel articulation of these emergent regularities and patterns within the real. The causal relations that scientific laws and discoveries articulate are expressions of the way the real immanently limits its own potentials and unfolding. But, at the same time, these regularities and patterns open up a field that, while still beholden to the limits set by regularities and patterns, is a field of potential that outstrips what has actually happened or what will eventually happen. In this respect, while the history of the real, causal relations, and "natural laws" limit what can happen in the real, they also open up the possibility for what could have happened in the real. As I have mentioned, I call this field that emerges from the real, but which still outstrips its actuality, "the universe." As a field of potential, the universe is still delimited by causal relations and natural laws. But, at the same time, it

${ }^{8}$ See Jane Bennett and Bruno Latour for the idea that material things are not simply static objects, but also active contributors to the material context in which they unfold. 
preserves the contingency and the possibility of novel emergence within the real.

\section{b) The Real as Contingent and Emergent}

There are a number of problematics that accompany the thought of the contingency and emergence of the real, and I cannot deal with all of them here. First, there is the contingency of the real as a whole, the uncaused origin of the real per se-its uncaused emergence ex nihilo. ${ }^{9}$ Second, there is the contingency of each individual real thing. This has two sub-problems: its own uncaused emergence as an individual and its emergent character during its free or contingent act of existence. Third, there is the criticism of previous conceptions of causality that would imply a lack of contingency in and of the real. Fourth, there is the description of causal relations such that they allow for contingency and emergence within the real. ${ }^{10}$ Fifth, there is the emergence of novelty or new types of real things and how this occurs within the limits of material causality. In the following, I will limit myself to the second sub-problem of the second mentioned problematic because it is this problematic that most pointedly indicates the ontological independence of the real from the intentional relation.

Even though the field of potential called the universe is limited by the history of the real, its regularities and patterns, causal relations, and "natural law," it nevertheless preserves the contingency and emergent capacity of the real. The universe is nothing other than the materially limited potential that the real opens up for itself given its specific history. Yet the potentials of the universe exceed what actually happens in the real. By preserving the contingency and emergent capacity of the real, the universe preserves the realness of the real as something that is, in every individual case, irreducibly unique and singular.

At any given time in its act of existing, each real thing is opened up to a range of potentials for how it will continue to actualize its existence. Again, causal relations limit this range of potentials. This range of potentials is nested within the material regularities that affect the real thing (given the type of real thing it is) and those by which it will affect others and continue to constitute its material context. It thus refers to the various and contingent ways that a thing can respond to being affected by others, the way it will be itself (and its type) with regard to being affected by others, and the way it

\footnotetext{
${ }^{9}$ This problematic of the ontological origin of the real as a whole is indicated and implied, if followed through radically, in Martin Heidegger's critique or critical delimitation of the principle of sufficient reason from the thought of Being (Heidegger, The Principle of Reason).

${ }^{10}$ Such a criticism of traditional theories of causality and a new description of a theory of causality that does not follow a deterministic model has been offered by a number of sources, including Friedrich Nietzsche (297-298), Louis Althusser, Jane Bennett (41), and Bruno Latour.
} 
will — in being itself and its type — affect others and help forge the actual material context around it. The actualization of any potential in the act of existing is a selection from this prior and broader range of potential actualizations. ${ }^{11}$ Each and every thing emerges from this prior range of potentials available to it into a material context as it actualizes a limited number of them. The selection from this prior and broader range of potentials, the actualization of one or some of them in the act of existing, is contingent. Although causal relations regulate this contingency, the act of selecting which potential will be actualized is never fully determined by the real context in which the thing finds itself, nor by the other real things that affect it. There will always be a free, yet limited selection from a range of potentials that the real thing has to enact itself.

Every act of existence has its own freedom and "agency" for how it itself turns out and how it will affect others that cannot be reduced to the particular material context it actualizes itself within. This freedom can be seen in the way every individual thing withdraws from this actual context and selects, from a range of potentials available to it in the universe, how it will continue to actualize itself. And its emergence from this field of potential into the material context helps constitute the very character of the context. Yet even once it has selected a potential to actualize and actualizes it accordingly, every real thing could have been otherwise. In other words, every individual thing is not only constituted by those potentials it has selected to actualize, but also by those potentials that it could have actualized. It is in this way that we could never say that the real thing itself is "seen from everywhere" or that it is the sum total of its relations to all other things. ${ }^{12}$ For the real thing's concept includes within it the real potentials that have never been actualized, but could have been. The unactualized potentials that belong to each and every real thing are an excess within it that cannot be reduced to its given or actualized material relations with other real things.

11 To speak of acts of existing and selections of potential does not necessarily mean conscious or purposive acts or selections. An act or a selection, in the way I am using the terms, need not be conscious or purposive. These can be accidental, as with non-living things. But even here, these would be an accident that arises from a contingency and the potentials for actualization that belong uniquely to each and every real thing. These can also, of course, be conscious or purposive as they often are (though not always) with living things.

${ }^{12}$ In this respect, (and like Harman) we could not follow Maurice Merleau-Ponty in saying that the thing itself is it as seen "from everywhere" (Merleau-Ponty 79). Nor could we follow Leibniz's early idea of the individual's complete concept, which is defined by the sum total of its actual relations to all other things from the beginning to the end of time (Leibniz 12-15). 


\section{c) The Real as Independent}

The realness of the real lies between its act of existing and the real potentials it could have actualized. Every real thing must accomplish its act of existing on its own and for itself. Only it, whatever kind of real thing it is, can accomplish its act of existing because only it can select from the range of potentials available to it at every moment in order to actualize itself in a given way. These potentials and actualizations belong uniquely to it as an individual. Each individual real thing is independent from others, then, not in the sense that it can accomplish its act of existing in the absence of all other things, but rather in the sense that its act of existence is itself an independently achieved act-even though it must occur in the context of other things. This is the most general sense of the independence of the real.

More specifically, the independence of the real refers to the independence of the real from human beings. This second sense of the real's independence is founded upon the first. However, it also has the added dimension that the context of things within which the real actualizes itself need not include the human being. That is, while every real thing must actualize its existence alongside other things, the human being is not a necessary "thing" in this context. Or, we could say that the human is not necessarily a limiting, causal condition on the actualization of the real. With regard to the first point, the sense of realness that the human understands when it encounters a real thing includes within it the independent act of existence of this thing. Already, this implies that the thing has an independent act of existing with regard to the rest of the real things around it, including any human being, in the first sense described above. With regard to the second point, the thing's sense of realness then also indicates that the human need not exist in order for this real thing to exist. It need not, because the material limitations set upon the real in its movement from potential to actualization do not include the necessary presence of the human. This act can be accomplished by each and every real thing with or without the presence of the human in the real. Although the human definitely influences the real while it is within it, there is nothing about the human itself that the rest of the real is materially dependent upon for its own act of existing. That is, the range of potentials from which the nonhuman real selects to actualize itself may include the human, but it also may not. We will now turn to this detachability of the human from, as well the emergent additive it contributes to, the range of potentials available for the rest of the real.

\section{The Real and the Human}

The first thing to note is that the human being is a real being in the universe. The human being is part of the real, but not a necessary part of it. What we today call "human being," or homo sapiens sapiens, emerged into the real 
between a hundred and two-hundred thousand years ago. But, and this is the important point, just as all other real beings, it need not have. Its emergence was contingent or non-necessary. ${ }^{13}$ Even though the earth and life prior to human emergence prepared the conditions for its emergence, many things could have happened that might have brought its evolutionary line to a dead end. Or (debatably), the genetic mutations that eventually led to the emergence of the human being, giving its distinctiveness from other homo sapiens, may simply have never occurred. ${ }^{14}$ Keeping this contingency of human emergence in mind, we can say the following about intentionality.

First, the necessary link between thought and being (to recall the correlationist problematic) or the necessary relation between the human subject and what it intends only applies after the human has already emerged in the real. That is, the formal necessity of a relation between a human subject and its intended object is itself a "contingent necessity" that only arises because the conditions for this necessity have themselves contingently emerged in the real-namely, the emergence of the human subject. So, while formally conceived, there is a necessary link between thought and being, this link itself need not have emerged. The human subject that intends the real need not have emerged in the real. And this recognition is phenomenologically contained in the very thought of the real. It gives orientation to the intentional relation in its sense of the real, but, by intending it, it does not negate that to which this sense refers (i.e., the objective independence of the real).

Furthermore, the intentional relation is not an enclosed representational sphere that has not always already been exposed to that which lies outside of the human being. This contingency of intentionality is recognized "in" intentionality itself precisely through the "ascription" of realness to a real thing. This "ascription" is not a subjective "projection" that first crosses a chasm between the human "mind" and external reality. It is rather the recognition of the ontological status of the real to which the human has already been exposed. The sense of realness given by the real

13 There is a debate in evolutionary science about contingency and convergence, represented by Stephen Jay Gould and Simon Conway Morris. Gould, arguing for contingency, held that if the earth's evolutionary history was repeated, it would turn out very differently. Morris, arguing for convergence, held that the evolution of life might be different, but that it would nevertheless tend towards the same achievements, including intelligence. Nevertheless, even if one takes a convergent approach to evolution, there still would be nothing necessary about the human per se. Another intelligent being could have evolved instead of the human.

${ }^{14}$ From the perspective of the theory of the real that I have been tracing out above, there is an added complication with human being that I will not be able to address here. The human being is not just exposed to the real and to the universe (the field of real potentials), but also to the nonreal - a field of potentials that cannot be actualized in the real and which outstrip the known universe, because they exceed material and causal limits. 
refers to the objective realness of the real itself, which is independent from the human who recognizes it. However, the sense of the real is dependent upon the presence of the human since it is formally conceived of as a sense for the human. But this sense refers to the objective independence of the real from the human. Intending the real as real, does not then negate the independence of the real either in the sense of realness or in the objective realness to which it refers. To intend the real is to intend that which is not dependent upon the human's presence for its existence or its act of existing because the real can be without the presence of the intentional relation. With regard to the real, intentionality does not then close the human into an insulated mental sphere. It rather always already exposes the human to that which is independent from the intentional relation. This prior exposure to the real is the very condition for being able to know or to deny knowing the real. ${ }^{15}$ And this very exposure indicates that the real is the material condition for the possibility of the intentional relation.

How is it that the real is the material condition of possibility for intentionality? And, more specifically, how is this ontological independence of the real such a condition? We can address these questions by asking: what is an idea?

An idea with regard to the real is not an inner representation in an encapsulated mind. This is a hypostatization and reification of what an idea really is. An idea is rather the condensation of a potential - in this case, the condensation of a real potential. Or, more pointedly, it is a condensed sense that indicates a temporally extended potential within the real/universe to follow out and actualize (or not). It is a condensed sense in that it grasps, from a present moment, the temporal-spatial unfolding of a materially limited potential of the real. With regard to the real, human intentionality is guided by such ideas of the real; it is the grasping of potentials in and of the real as they are in the process of unfolding (or not). In order for an idea about the real to come into intentionality, intentionality must first be exposed to the real and its potentials.

There is a complication, however, because once the human is amongst the real, the human adds to the range of potentials available to the real. There are a couple of things to be said here. First, the relation between the human and the rest of the real is emergent in the sense that the presence of the human within the real unlocks novel potentials for the rest of the real and unleashes new potentials into the universe. For instance, for a real tree

15 This argument follows the logic of other non-representational, phenomenological arguments about perception such as Husserl's and Heidegger's. There is always already a prior appearance or disclosure, from which any representation can then be judged to be true or false. If there was not this prior disclosure, then there would be no way to make the truth-value judgment in the first place. The judgment would have nothing to compare the representation with in order to make a truth-value judgment about it. 
to have the potential to be cut down and be fashioned into a table, a tablemaking being must be present in the real. If no table-making being is present, then the potentials within the tree that make it suitable for such a thing as a table remain locked immanently within it. Before the emergence of the table-making being, the universe does not contain the potential for a table, nor for trees to be turned into tables. The material preconditions for such a potential are locked in the tree. The qualities of its wood (pliancy, hardness, durability) that make it suitable for a table are not opened up to the potential to be turned into a table. For this to happen, a table-making being must be present. When there is such a being, such as a human being, then it unlocks this potential for the tree to be turned into a table and unleashes the potential for trees to be turned into tables out into the universe. However, it would be a mistake to then think that this potential for trees to be fashioned into tables has its ontological origins solely in the human.

The human does not create the potential to turn a tree into a table $e x$ nihilo. Rather, the relation between the human and the tree unleashes this potential into the universe that is irreducible to either the human or the tree by themselves. For instance, the material qualities (pliancy, hardness, durability) that make the tree suitable for a table reside objectively in the tree, independently from the human. They would be there in the tree even if the human was not present. For instance, it is the same hardness of the tree that can stand up to the wind (with or without the human) that can also serve as the material basis for a table. But if the human was not present, these qualities would belong to the tree and be participating in other potentialsone of which is not to be turned into a table. While the qualities that make a tree suitable for a table reside objectively and independently in the tree itself, these same qualities enter into new and emergent potentials when there is a table-making being present in the real. There is then the need for the objective existence of, in this case, the human being for the tree's otherwise independent qualities to have the potential for a table. The human's need (for instance, to build tables for eating) introduces a new potential for the tree's qualities that make it suitable to meet such a need. We can call this characteristic of the potentials that stem from the real, but which only become unlocked from it and unleashed into the universe by way of the presence of the human within the real, transobjective potentials. ${ }^{16}$ They are trans- objective, because they "cross" an objective

${ }^{16}$ Here, I am specifically speaking about transobjective potentials that belong to the relation between the human and a tree. This is not to suggest that such transobjective potentials do not also occur with regard to the relations between nonhuman beings, neither of which are human. But the point here is to indicate the distinctiveness of the way that transobjective potentials serve as the basis for the human's intentional relation and its ideas about the real. 
relation in the real. They require the objective, yet independent existence of the relating beings in order to be unleashed. ${ }^{17}$

With regard to the real and the human's place in the real, ideas are the condensations of transobjective potentials. The idea or sense of realness is one such transobjective potential. The objective realness or independent existence of a real thing is not dependent upon the presence of the human. However, once the human is within the real, then the "objective" realness of the real is unlocked such that it can be the reference of an idea or sense for a sense-oriented being such as the human. The real and its realness exposes the human to the field of the real, opening up the potential for the intentional relation and its ideas/senses with regard to it. And this exposure unlocks the potential of an intentional relation between an intending subject and an intended object, which does not-by way of this exposure-reduce the referent to being a mere product or representation of the subject. Exposure is not an "inside-out" movement, from the human to the real; it is rather an "outside-in" movement, from the real to the human. This exposure to the real, and the sense of realness by which human beings exist, is the precondition for any kind of advanced theoretical activity such as science or philosophy. Its most basic experience is the practical struggle to survive in and amongst the real. That is, the attempt to keep forging the material conditions that favor a human act of existing, or, more broadly conceived, a way of life.

\section{Conclusion: Exposure, Survival, Withdrawal, and Excess}

We are now in a position to offer a few points about this phenomenological approach to the real and speculative realism. As I have been indicating, being exposed to the real presupposes an experience of struggle for survival that is prior to any speculative philosophy, even a speculative realism. The human being does not first gain access to the real through absolute knowledge or mathematics, as Meillassoux would argue; rather, the human being first of all exists in an exposed state with regard to the real. The first access to the real, then, is through the intuitive following out or avoidance of potentials and regularities within the real that can help it or destroy it in this struggle. Just because this struggle is primarily practical and not at first oriented to any absolute knowledge does not mean that the intentional relation through which it carries out its struggle is not already exposed to the independent field it exists within and which threatens to be (again)

${ }^{17}$ There is also an ontological asymmetry here that I will not describe. While it can be said that a tree does not depend upon these transobjective potentials unleashed by the human for its existence, there is a sense in which the human's existence depends upon the presence of trees. This can be understood in evolutionary terms. But it can also be understood more formally and in a phenomenological sense in the way that the emergence of novelty in the real depends upon what has preceded it in the real. 
without the human. The human can know the real in its realness even without absolute knowledge about it.

Furthermore, this exposure and struggle also indicate that the human comes to know this realness of the real primarily through the appearance of the real and in relation to it, not by first postulating an inaccessible realm beyond all relations as Harman suggests. The intentional relation with regard to the real neither exhausts the individuality of any real thing, nor is it completely out of touch with the excess within each and every real thing. The intentional relation does not exhaust the depths of every real thing since it recognizes that the realness of the real is more than its actuality. The realness of the real is also contained in the way it withdraws from its actuality and holds itself in reserve for potentials that it may or may not actualize. As the intentional relation follows out certain practical activities with real things, it also knows that the potentials in the real it is following may not work out. Even beyond "not working out," the intentional relation recognizes that any given real thing could have been otherwise. However, at the same time, the field of real potentials that remains in excess of all actual relations is not wholly inaccessible or unknown. Because of the material and causal limits of this field of potential, the human progressively comes to know the limits of these real potentials (actualized or unactualized) through the struggle to survive, practical activity, and later through scientific knowledge. Because these unactualized potentials follow the regularities and patterns of the real, this field is knowable-however finitely. Instead of then postulating an inaccessible metaphysical realm above and beyond all relations to preserve the individuality of each and every real thing, we need only recognize that the universe can be a complex, sometimes chaotic, but always mysterious place.

\section{Works Cited}

ALTHUSSER, Louis. "The Underground Current of the Materialism of the Encouter." Philosophy of the Encounter. Later Writings, 19781987. New York: Verso Books, 2006.

BENNETT, Jane. Vibrant Matter. A Political Ecology of Things. Durham: Duke University Press, 2010.

HARMAN, Graham. "On Vicarious Causation.” Collapse: Philosophical Research and Development 2 (2007): 187-221.

—. The Quadruple Object. New York: Zero Books, 2011.

-. "The Well-Wrought Broken Hammer: Object-Oriented Literary Criticism.” New Literary History 43 (2012): 182-203. 
—. "The Current State of Speculative Realism." Speculations: A Journal of Speculative Realism 4 (2013): 22-28.

HARVEY, Charles and Jim D. Shelton. "Husserl's Phenomenology and the Ontology of the Natural Sciences." Phenomenology of Natural Science. Eds. Lee Hardy and Lester Embree. Boston: Kluwer Academic Publishers, 1992: 119-133.

HAWKING, Stephen and Leonard Mladinow. The Grand Design. New York: Bantam Books Trade Paperbacks, 2010.

HEIDEGGER, Martin. Kant and the Problem of Metaphysics. Bloomington: Indiana University Press, 1973.

—. "Science and Reflection." The Question Concerning Technology and Other Essays. New York: Harper Perennial, 1977.

—. The Principle of Reason. Bloomington: Indiana University Press, 1996.

—. "The Thing." Poetry, Language, Thought. New York: Harper Perennial, 2001.

—. "Building, Dwelling, Thinking." Poetry, Language, Thought. New York: Harper Perennial, 2001.

- The Concept of Time. The First Draft of Being and Time. New York: Continuum, 2011.

HUSSERL, Edmund. Ideas Pertaining to a Pure Phenomenology and to a Phenomenological Philosophy. First Book. Boston: Martinus Nijhoff Publishers, 1983.

LATOUR, Bruno. We Have Never Been Modern. Cambridge: Harvard University Press, 1993.

LEIBNIZ, Gottfried W. Discourse on Metaphysics. La Salle: Open Court Publishing, 1993.

MEILLASSOUX, Quentin. After Finitude: An Essay on the Necessity of Contingency. New York: Continuum, 2009.

MERLEAU-PONTY, Maurice. Phenomenology of Perception. New York: Routledge, 1958.

NIETZSCHE, Friedrich. The Will to Power. New York: Vintage Books, 1968.

SARTRE, Jean-Paul. Being and Nothingness. Trans. H. E. Barnes. New York: Washington Square Press, 1956.

SPARROW, Tom. The End of Phenomenology. Metaphysics and the New Realism. Edinburgh: Edinburgh University Press, 2014. 
ZAHAVI, Dan. "The End of What? Phenomenology vs. Speculative Realism." International Journal of Philosophical Studies 24 (2016): 289-309. 